\title{
Cyclin-C-dependent cell-cycle entry is required for activation of non-homologous end joining DNA repair in postmitotic neurons
}

\author{
A Tomashevski ${ }^{1}$, DR Webster ${ }^{2}$, P Grammas ${ }^{1,3}$, M Gorospe $^{4}$ and II Kruman ${ }^{\star, 1,3}$
}

It is commonly believed that neurons remain in $\mathrm{G}_{0}$ phase of the cell cycle indefinitely. Cell-cycle re-entry, however, is known to contribute to neuronal apoptosis. Moreover, recent evidence demonstrates the expression of cell-cycle proteins in differentiated neurons under physiological conditions. The functional roles of such expression remain unclear. Since DNA repair is generally attenuated by differentiation in most cell types, the cell-cycle-associated events in postmitotic cells may reflect the need to re-enter the cell cycle to activate DNA repair. We show that cyclin-C-directed, pRb-dependent $G_{0}$ exit activates the nonhomologous end joining pathway of DNA repair (NHEJ) in postmitotic neurons. Using RNA interference, we found that abrogation of cyclin-C-mediated exit from $G_{0}$ compromised DNA repair but did not initiate apoptosis. Forced $G_{1}$ entry combined with prevention of $G_{1} \rightarrow S$ progression triggered NHEJ activation even in the absence of DNA lesions, but did not induce apoptosis in contrast to unrestricted progression through $G_{1} \rightarrow S$. We conclude that $G_{0} \rightarrow G_{1}$ transition is functionally significant for NHEJ repair in postmitotic neurons. These findings reveal the importance of cell-cycle activation for controlling both DNA repair and apoptosis in postmitotic neurons, and underline the particular role of $G_{1} \rightarrow S$ progression in apoptotic signaling, providing new insights into the mechanisms of DNA damage response (DDR) in postmitotic neurons.

Cell Death and Differentiation (2010) 17, 1189-1198; doi:10.1038/cdd.2009.221; published online 29 January 2010

Due to continuous exposure to genotoxic stress resulting from exogenous and endogenous sources, protection of genomic integrity is a major challenge for living cells. Failure to repair DNA lesions often leads to cell death, genomic instability, and tumorigenesis. ${ }^{1,2}$ Terminally differentiated neurons are highly susceptible to oxidative DNA damage due to their high rate of oxidative metabolism. ${ }^{3}$ For this reason, DNA repair is highly important for these cells. ${ }^{2,4}$ The mechanisms of DNA repair have been investigated mainly in proliferating cells. In these cells, the cell-cycle machinery is a part of the DNA-damage response (DDR), involved in both DNA repair and apoptosis. ${ }^{5}$ DNA repair in terminally differentiated cells is not expected to be linked to the cell cycle. However, increasing evidence indicates that the cell-cycle machinery plays a key role in different processes in terminally differentiated cells; ${ }^{6,7}$ for example, cell-cycle activation is essential for apoptotic signaling in neurons. ${ }^{3,8,9}$ Expression of cell-cycle proteins has been observed at physiological conditions in terminally differentiated neurons, ${ }^{7}$ but the functional relevance of this expression remains unknown. Since DNA repair is generally attenuated by differentiation in most types of cells, ${ }^{10,11}$ the expression of cell-cycle-related proteins may reflect the need of resting cells to re-enter the cell cycle in order to activate DNA repair. Our recent data demonstrating that cell-cyclerelated proteins are expressed in neurons exposed to repairable DNA damage, also support the existence of a link between the cell-cycle machinery and DNA repair in postmitotic cells. $^{12}$

Although cells in most mammalian tissues enter a terminally arrested $\left(G_{0}\right)$ phase at some point during their life, the mechanisms regulating the maintenance of $G_{0}$ and $G_{0} \rightarrow G_{1}$ transition are not fully understood. The retinoblastoma protein (pRb) plays a crucial role in cell-cycle regulation. ${ }^{13}$ Recently, the cyclin-C/cyclin-dependent kinase-3 (CDK3) complex was shown to facilitate exit from $\mathrm{G}_{0}$ into the cell cycle by $\mathrm{pRb}$ phosphorylation at serines (S) 807 and 811 . This cyclin-Cassociated kinase activity peaked shortly after mitogenic stimulation of quiescent cells in early $G_{1} \cdot{ }^{14}$ During exit from $\mathrm{G}_{0}$, the cyclin-C/CDK3 complex directed pRb phosphorylation at $5807 / 811$ in a temporal pattern that preceded $\mathrm{pRb}$ phosphorylation by cyclin-D/CDK4, cyclin-D/CDK6, and cyclin-E/CDK2. ${ }^{14}$ The levels of cyclin-E protein and associated kinase activity rise in the late $G_{1}$ phase. ${ }^{15}$

As double-strand breaks (DSBs) are the most lethal form of DNA damage, ${ }^{16}$ maintenance of genomic integrity depends on efficient and accurate DSB repair. Mammalian cells repair DSBs by two pathways: homologous recombination and non-homologous end-joining (NHEJ). NHEJ is predominant in mammalian cells. ${ }^{17}$ NHEJ starts with the binding of Ku70/Ku80 (Ku) heterodimer to the broken DNA

\footnotetext{
${ }^{1}$ Garrison Institute on Aging, Texas Tech University Health Sciences Center, Lubbock, TX, USA; ${ }^{2}$ Department of Cell Biology and Biochemistry, Texas Tech University Health Sciences Center, Lubbock, TX, USA; ${ }^{3}$ Department of Neurology, Texas Tech University Health Sciences Center, Lubbock, TX, USA and ${ }^{4}$ Laboratory of Cellular and Molecular Biology, National Institute on Aging, National Institutes of Health, Baltimore, MD, USA

*Corresponding author: II Kruman, Garrison Institute on Aging and Department of Neurology, Texas Tech University Health Sciences Center, Lubbock, TX 79430, USA. Tel: + 1806743 2820; Fax: + 1806743 2698; E-mail: inna.kruman@ttuhsc.edu

Keywords: neuron; DNA repair; cell cycle; DNA damage; apoptosis

Abbreviations: CDK, cyclin-dependent kinase; CKI, cyclin-dependent kinase inhibitor; DNA-PKcs, DNA-protein-kinase catalytic subunit; DSB, double-strand break; NHEJ, non-homologous end joining; pRb, retinoblastoma protein; siRNA, small interfering RNA; DDR, DNA damage response

Received 14.8.09; revised 26.10.09; accepted 10.11.09; Edited by N Bazan; published online 29.1.10
} 
ends. Ku facilitates the recruitment of Artemis-DNA-proteinkinase catalytic subunit (PKcs) complex, which processes the ends to prepare them for ligation. ${ }^{17}$

In this study, we found that activation of NHEJ in postmitotic neurons was accompanied by phosphorylation of $\mathrm{pRb}$ at S807/811 directed by cyclin-C-associated kinase activity, which was previously shown to be sufficient for $G_{0} \rightarrow G_{1}$ transition. ${ }^{14}$ The abrogation of cell-cycle entry compromised NHEJ repair, while forcing $G_{1}$ entry caused NHEJ activation even in the absence of DNA lesions. Together, these results suggest the need for resting cells to re-enter the cell cycle to activate the NHEJ repair machinery.

\section{Results}

$5 \mu \mathrm{M} \quad \mathrm{H}_{2} \mathrm{O}_{2}$ generates repairable DSBs in postmitotic neurons. To investigate the effect of non-lethal DSBs on neurons, we exposed postmitotic rat cortical neurons to repairable DNA damage generated by hydrogen peroxide $\left(\mathrm{H}_{2} \mathrm{O}_{2}\right) . \mathrm{H}_{2} \mathrm{O}_{2}$, a product of normal oxygen metabolism, is extensively used to induce oxidative stress in cell culture cell models and is known to induce DSBs. ${ }^{12,16}$ Cultures of cortical neurons, according to our previous results, yielded $\sim 99 \%$ pure neuronal populations. The purity of neuronal populations was controlled by the expression of the specific neuronal marker, NeuN (data not shown). Previously, we demonstrated that $5 \mu \mathrm{M} \mathrm{H}_{2} \mathrm{O}_{2}$ induces repairable DSBs and does not induce apoptosis in postmitotic cortical neurons. ${ }^{12}$ We used phosphorylated $\mathrm{H} 2 \mathrm{AX}(\gamma \mathrm{H} 2 \mathrm{AX})$ as a marker of DSB formation. ${ }^{12}$ The kinetics of $\gamma \mathrm{H} 2 \mathrm{AX}$ accumulation demonstrates the repairable character of DSBs induced by $5 \mu \mathrm{M} \mathrm{H}_{2} \mathrm{O}_{2}$, as illustrated by a significant increase in $\gamma \mathrm{H} 2 \mathrm{AX}$ expression compared with that in untreated neurons, followed by its significant reduction (Figure 1a). The analysis of apoptotic markers, including cleavage of caspase-3 (Figure 1b) and examination of apoptotic neuron nuclei (data not shown), revealed that by $24 \mathrm{~h}$ after exposure a
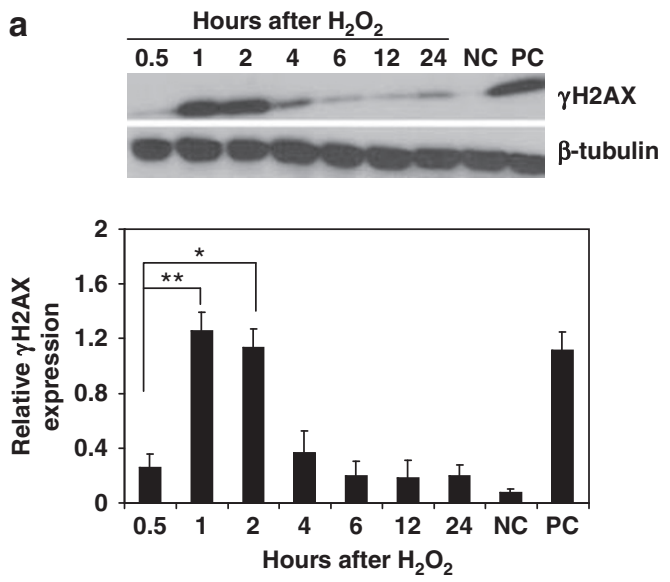

d

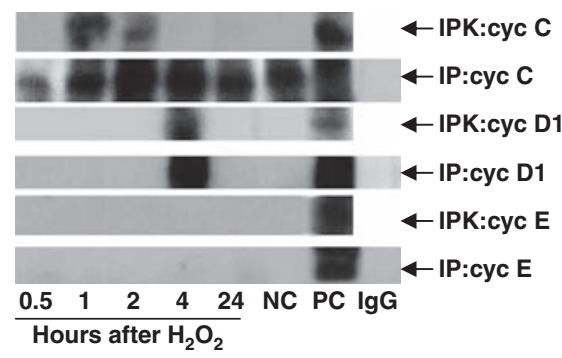

e

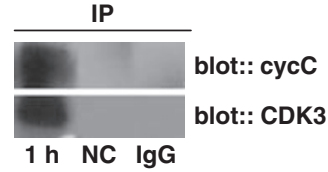

b

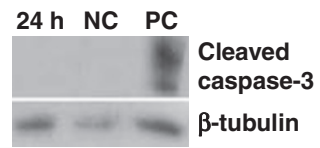

C
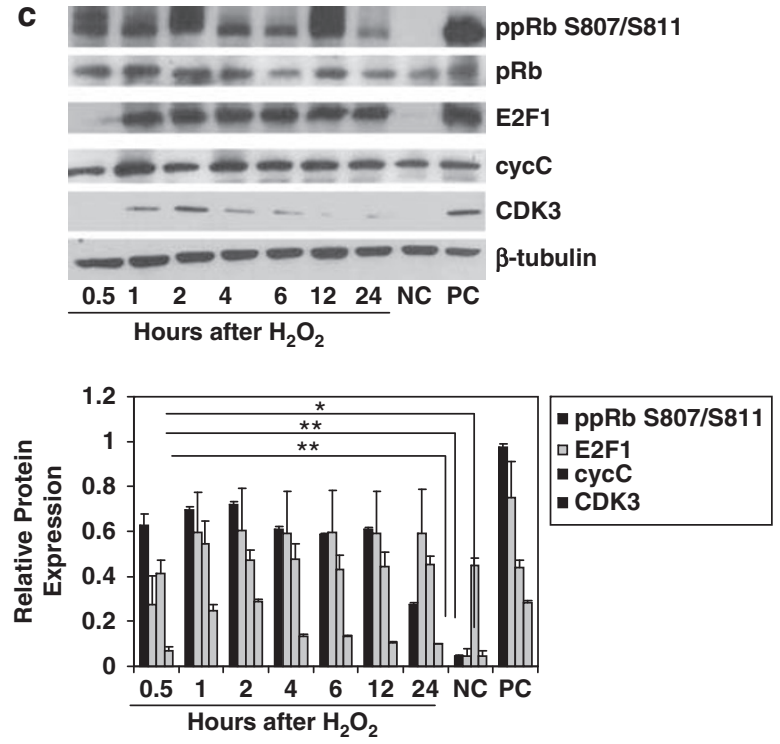

Figure 1 DSB induction is associated with the cell-cycle entry of postmitotic cortical neurons. (a, b) Immunoblot analysis of $\gamma \mathrm{H} 2 \mathrm{AX}$ and apoptotic caspase-3 cleavage in neurons treated with $5 \mu \mathrm{M} \mathrm{H}_{2} \mathrm{O}_{2}$. Negative control (NC): untreated cultures; positive control (PC): extract from staurosporine-treated Jurkat cells. The values are the means and S.D. $(n=5) ;{ }^{*} P<0.002 ;{ }^{* *} P<0.001$. (c) Immunoblot analysis of the expression of cell-cycle-related proteins in neurons exposed to $5 \mu \mathrm{M} \mathrm{H}_{2} \mathrm{O}_{2}$. Negative control (NC): untreated neurons; positive control (PC): extracts from proliferating HeLa cells. The values are the means and S.D. $(n=4) ;{ }^{*} P<0.002 ;{ }^{* \star} P<0.001$ compared with corresponding NC. (d) Lysates from cortical neurons were prepared at the indicated times and subjected to immune precipitation (IP) using anti-cyclin-C, anti-cyclin-D1 and anti-cyclin-E. Precipitates were tested for in vitro kinase activity using Rb-769 as substrate (IPK). Negative control (NC): untreated neurons; positive control (PC): proliferating HeLa cells. Isospecific control (IgG): normal rabbit or mouse lgG. (e) Lysates from cortical neurons treated with $5 \mu \mathrm{M} \mathrm{H}_{2} \mathrm{O}_{2}$ were subjected to immunoprecipitation followed by immunoblot analysis. Anti-cyclin-C precipitates were analyzed using anti-CDK3 antibody and anti-CDK3 precipitates were analyzed using anti-cyclin-C antibody. Normal rabbit $\lg G(\lg G)$ was used as control for both anti-CDK3 and cyclin-C antibodies 
to $5 \mu \mathrm{M} \mathrm{H} \mathrm{H}_{2} \mathrm{O}_{2}$, the neuronal cultures did not undergo apoptosis, consistent with our data on $\gamma \mathrm{H} 2 \mathrm{AX}$ expression. Previously, we demonstrated the repairable character of DSBs generated by $5 \mu \mathrm{M} \mathrm{H}_{2} \mathrm{O}_{2}$ using comet assay and by testing apoptotic markers, cleavage of nuclear (Mcm3) and cytoplasmic ( $\beta$-actin) caspase-3 substrates. ${ }^{12}$

$\mathbf{G}_{\mathbf{0}} \rightarrow \mathbf{G}_{\mathbf{1}}$ transition in neurons exposed to DSBs. DSB induction was accompanied by early activation of cellcycle-regulatory proteins, including phosphorylation of $\mathrm{pRb}$ at $S 807 / 811$, required for $G_{0}$ exit ${ }^{14}$ and expression of transcription factor E2F1 (Figure 1c). E2F1 gene expression is known to rise as cells exit from $G_{0}$ and undergo $G_{0} \rightarrow G_{1}$ transition. ${ }^{13}$ Cyclin-C levels were high in postmitotic neurons, consistent with those seen in $\mathrm{G}_{0}$-arrested cells of nonneuronal origin ${ }^{14}$ and were not changed significantly after $\mathrm{H}_{2} \mathrm{O}_{2}$ treatment, although cyclin-C levels were typically highest by $1 \mathrm{~h}$ after treatment. Cyclin- $\mathrm{C}$ immunoprecipitates from lysates of cortical neurons revealed $\mathrm{pRb}$-kinase activity at 1 and $2 \mathrm{~h}$ after $\mathrm{H}_{2} \mathrm{O}_{2}$ treatment (Figure $1 \mathrm{~d}$ ). In contrast to cyclin-C, its partner CDK3 was not expressed in $\mathrm{G}_{0}$ neurons, but CDK3 levels significantly increased after $\mathrm{H}_{2} \mathrm{O}_{2}$ exposure (Figure 1c). Co-immunoprecipitation experiments demonstrate that the anti-CDK3 precipitate contains cyclin-C (Figure 1e). pRb-kinase activity associated with cyclin-D1 was not seen until at least $4 \mathrm{~h}$ of treatment (Figure 1d). No cyclin-E-associated pRb-kinase activity was found (Figure 1d). Coexpression of the neuronal marker NeuN and the marker of proliferating cells, $\mathrm{Ki}-67,{ }^{12}$ was observed in neurons by $1 \mathrm{~h}$ of $\mathrm{H}_{2} \mathrm{O}_{2}$ exposure but not in untreated neurons (Figure 2), confirming the entrance of postmitotic neurons into the cell cycle upon non-lethal DSB DNA damage. This suggests that the response to DSB formation in postmitotic neurons is associated with cyclin-C-directed $\mathrm{pRb}$ phosphorylation that precedes $\mathrm{pRb}$ phosphorylation directed by cyclin-D1, but is not associated with cyclin-Edependent $p R b$-kinase activity (late $G_{1}$ ). Such early $\mathrm{pRb}$ phosphorylation at $\mathrm{S} 807 / 811$ is consistent with previously observed $\mathrm{pRb}$ phosphorylation at $\mathrm{S} 807 / 811$ in T-lymphocytes and T98G cells during exit from $\mathrm{G}_{0} \cdot{ }^{14,18}$

Postmitotic neurons activate NHEJ upon DNA DSB damage. Next, we examined NHEJ activation in postmitotic neurons exposed to $5 \mu \mathrm{M} \mathrm{H}_{2} \mathrm{O}_{2}$. Since $\mathrm{Ku}$-DNA binding is crucial for NHEJ-mediated repair, ${ }^{17}$ we first assessed the DNA-binding activity of Ku proteins in neuronal extracts by immune recognition of an epitope on Ku70 or Ku86 that is accessible upon DNA binding. ${ }^{19}$ The analysis of NHEJ activity was performed based on in vitro end-joining of linearized plasmid DNA using cell-free extracts. ${ }^{20}$ This DNA-end ligation assay, which results in the formation of DNA concatemers, requires a functional NHEJ apparatus, as seen in the absence of DNA oligomers when using extract from untreated (undamaged) neurons (Figure 3b). Both Ku-DNA-binding and end-joining kinetics revealed early NHEJ activation (at 1-2 $\mathrm{h}$ after $\mathrm{H}_{2} \mathrm{O}_{2}$ exposure) followed by decrease of both parameters to levels seen in untreated cells (Figures $3 a$ and b). To relate NHEJ activation to neurons, we assessed the coexpression of the neuronal marker NeuN and DNA-PKcs phosphorylated at threonine (T) 2609 as a marker of activated NHEJ. As previously described, DNA-PKcs phosphorylation at this site is required for NHEJ activation, and mutations at the T2609 cluster severely compromised the ability of DNAPKcs to restore DSB-repair defects in DNA-PKcs-deficient cells. $^{21,22}$ The results of immunofluorescence analysis revealed the colocalization of both neuronal and NHEJ activation markers in cells at $1 \mathrm{~h}$ of $\mathrm{H}_{2} \mathrm{O}_{2}$ exposure but not in untreated cells (Figure $3 \mathrm{c}$ ). These data show that early and brief NHEJ activity is sufficient for DSB repair in postmitotic neurons exposed to a non-lethal DNA-damaging insult. Importantly, this timing of NHEJ activation coincided tightly with the timing of cyclin-C-associated pRb-kinase activity (Figure 1d), essential for $G_{0} \rightarrow G_{1}$ transition in postmitotic cells. Interestingly, pRb-kinase activity associated with cyclin-D1 was observed outside of the time frame of NHEJ activity (at $4 \mathrm{~h}$ after $\mathrm{H}_{2} \mathrm{O}_{2}$ exposure), although this activity was indeed

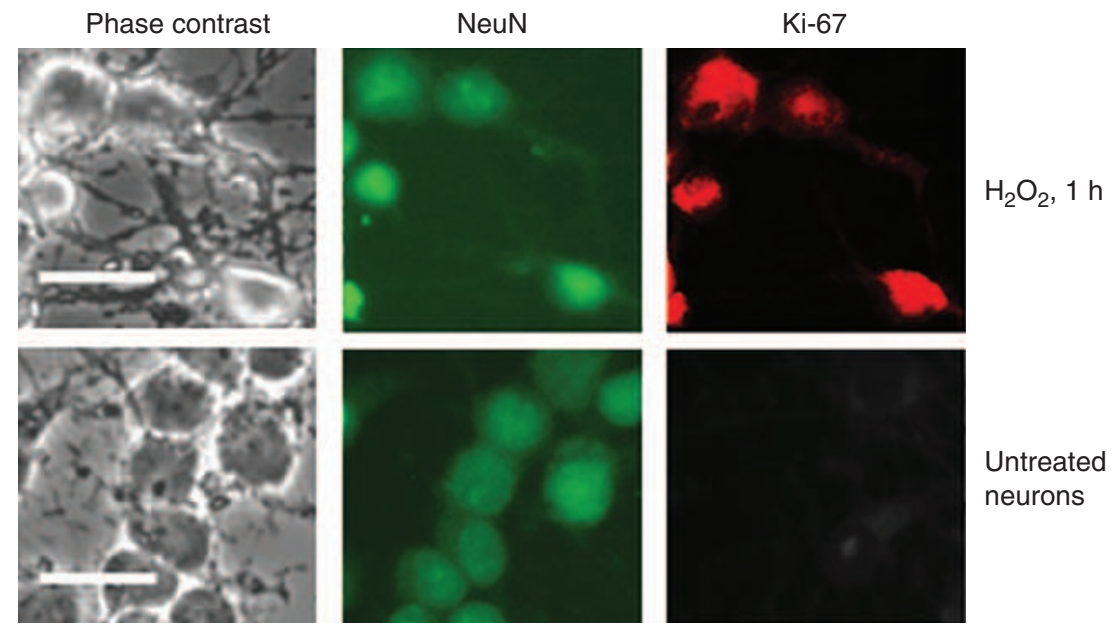

Figure 2 Coexpression of cell-cycle and neuronal markers in neurons at $1 \mathrm{~h}$ of $\mathrm{H}_{2} \mathrm{O}_{2}$ exposure. Coexpression of neuronal marker NeuN and a marker of active cell cycle, Ki-67, was detected by immunocytochemistry. Scale bars are $50 \mu \mathrm{m}$ 


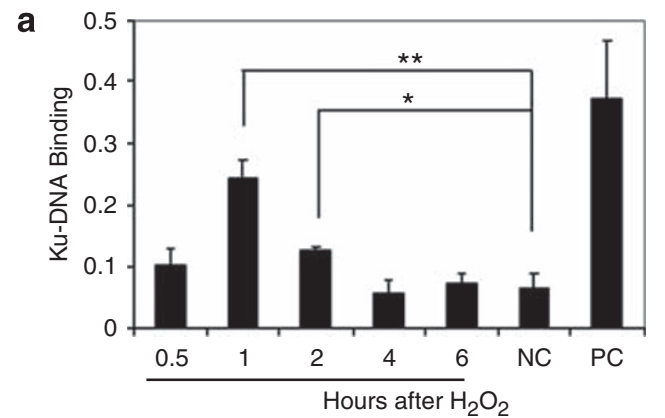

b
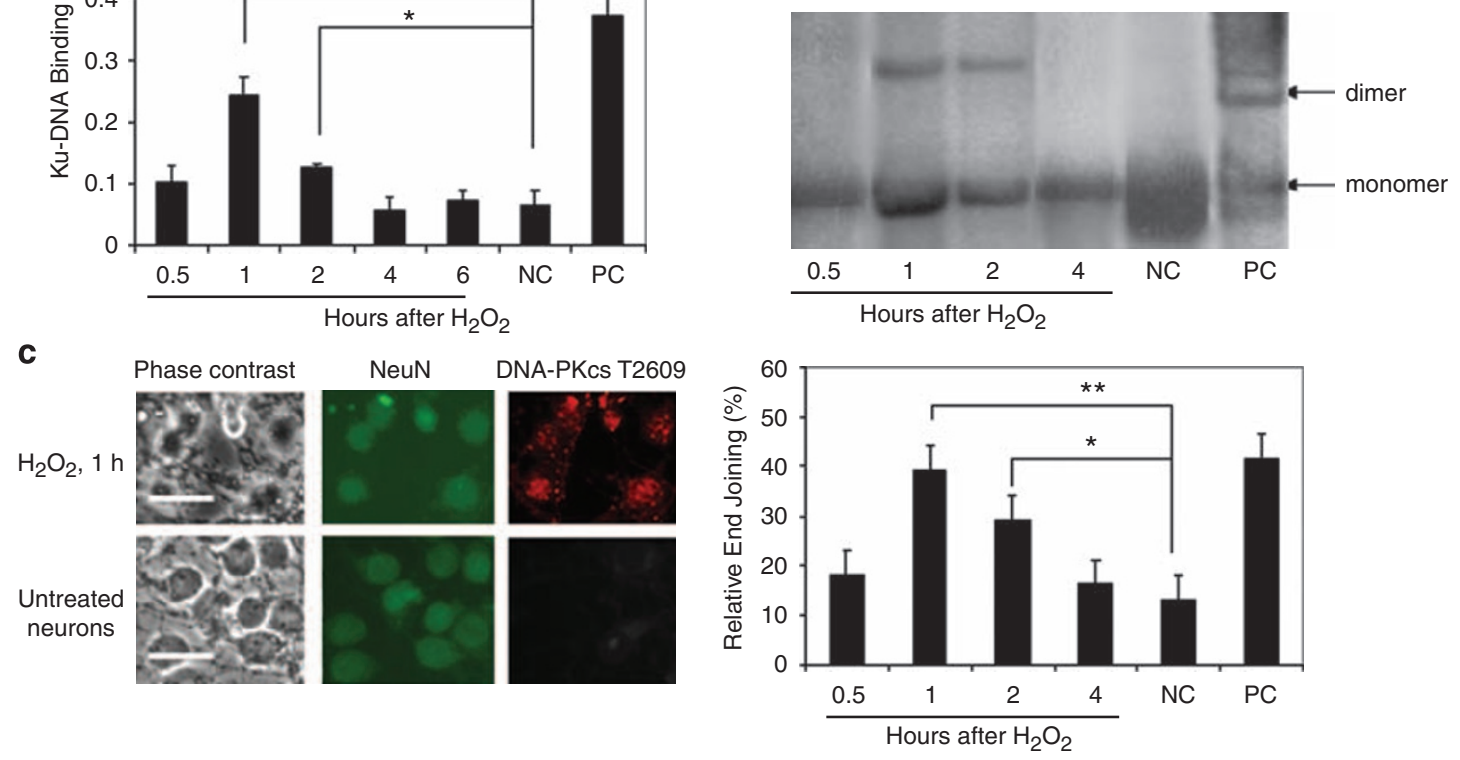

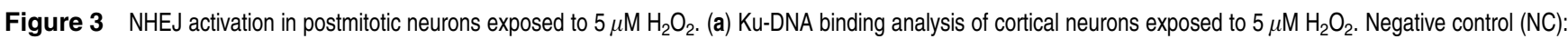
Untreated cultures; positive control (PC): the Raji nuclear extract. The values are the means and S.D. $(n=4) ;{ }^{*} P<0.02 ;{ }^{*} P<0.005$. (b) NHEJ analysis of cortical neurons exposed to $5 \mu \mathrm{M} \mathrm{H}_{2} \mathrm{O}_{2}$. DNA substrate was prepared by linearizing pGL3 basic, and was added to the NHEJ reaction. The products were subjected to electrophoresis $(0.8 \%$ agarose gel) and Southern blotting, hybridized with the ${ }^{32} \mathrm{P}$-labeled plasmid probe and visualized by autoradiography. Negative control (NC): untreated cultures; positive control (PC): T4 ligase-treated linearized plasmid DNA (pGL3 basic/Xhol). The values are the means and S.D. $(n=4) ;{ }^{*} P<0.05$; ${ }^{* *} P<0.002$. (c) Coexpression of neuronal marker NeuN and phosphorylated at T2609 DNA-PKcs as a marker of activated NHEJ repair was detected by immunofluorescence. Scale bars are $50 \mu \mathrm{m}$

induced in postmitotic neurons after DSBs, in contrast to cyclin-E-dependent pRb-kinase activity, which was not induced (Figure 1d).

Suppression of $G_{0} \rightarrow G_{1}$ transition attenuates NHEJ activation. To determine the functional role of cell-cycle activation and particular roles for cyclin-C- and cyclin-Dassociated phosphorylation of $\mathrm{pRb}$ in DSB repair in postmitotic neurons, we prevented $\mathrm{G}_{0} \rightarrow \mathrm{G}_{1}$ transition by silencing cyclin-C or Cdc25A. Cyclin-C suppression was previously shown to affect $G_{0}$ exit. ${ }^{14} \mathrm{Cdc} 25 \mathrm{~A}$ is a member of the cell division cycle-25 (Cdc25) family of proteins that function by dephosphorylating CDK subunits, and thereby activating the CDK/cyclin complex. Cdc25A is involved in the activation of cyclin-E- and cyclin-D1-associated kinase activities and $p R b$ phosphorylation. ${ }^{23}$ This suggests that Cdc25A suppression should not affect cyclin-C-associated $\mathrm{pRb}$ phosphorylation, which precedes $\mathrm{pRb}$ phosphorylation by cyclin-D/CDK4/6 and cyclin-E/CDK2.

The suppression of cyclin- $\mathrm{C}$ in cortical neurons by cyclin- $\mathrm{C}$ siRNA resulted in decreased levels of cyclin- $C$ protein and an almost complete blockade of cyclin-C-associated pRb-kinase activity (Figures $4 a$ and $b$ ), as well as cyclin-D1-associated pRb-kinase activity (data not shown). Cyclin-C silencing compromised DSB repair in neurons exposed to $5 \mu \mathrm{M} \mathrm{H}_{2} \mathrm{O}_{2}$, in contrast to neurons transfected with control siRNA, as evidenced by attenuation of both Ku-DNA-binding and endjoining activities (Figures $4 \mathrm{e}$ and $\mathrm{f}$ ). The lack of decrease in $\gamma \mathrm{H} 2 \mathrm{AX}$ levels in neurons transfected with cyclin-C siRNA that were treated with $5 \mu \mathrm{M} \mathrm{H}_{2} \mathrm{O}_{2}$ (Figure 4c), suggests that these neurons failed to repair the DSBs and supports the hypothesis that NHEJ is impaired by silencing cyclin-C. Interestingly, compromised DSB repair in these neurons did not lead to apoptosis, as evidenced by the absence of caspase- 3 cleavage. Basically the same pattern of change in NHEJ activity was observed in postmitotic neurons after reducing Cdc25A levels, although reduction of NHEJ activity tended to be lower than that in cells with suppressed cyclin-C (Figures $4 \mathrm{e}$ and $\mathrm{f})$. This may reflect a smaller suppression of Cdc25A protein expression. Surprisingly, Cdc25A suppression affected cyclin-C-associated pRb-kinase activity (Figure $4 b$ ), suggesting that Cdc25A is involved not only in cyclin-E- and cyclin-D1-associated kinase activities, ${ }^{23}$ but is also involved in cyclin-C-associated kinase activity.

Forced $\mathrm{G}_{1}$ entry causes NHEJ activation in the absence of DSB lesions. To further define the requirement of cellcycle re-entry for NHEJ activation in postmitotic neurons, we examined the effects of forced cell-cycle entry on NHEJ activation. To force cell-cycle reactivation, we suppressed p21 expression by siRNA. p21 is a cyclin-dependent kinase inhibitor (CKI), which is also involved in DNA-damage signaling and whose suppression by siRNA was previously shown to efficiently trigger DNA synthesis in primary, terminally differentiated skeletal muscle cells and quiescent fibroblasts. ${ }^{24}$ Reactivation of the cell cycle observed in quiescent cells upon overexpression of active cell-cycle factors, E2F1 and Cdc25A, or upon suppression of p21 was 
a
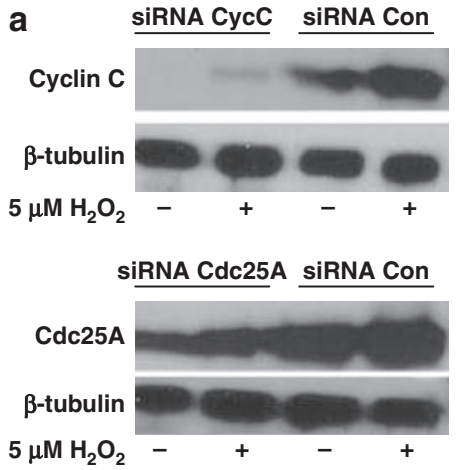

b
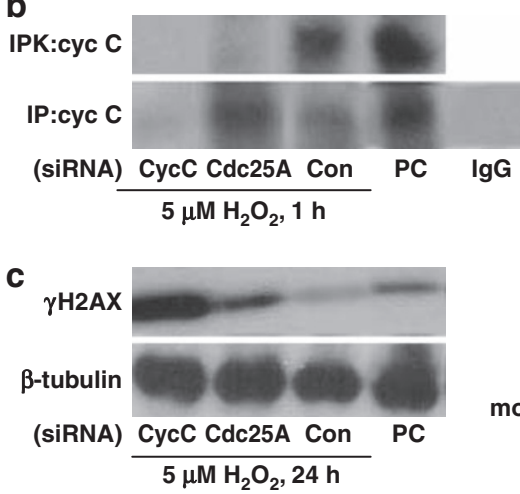

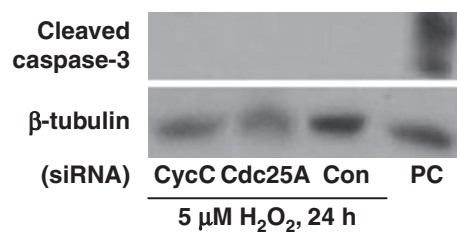

e

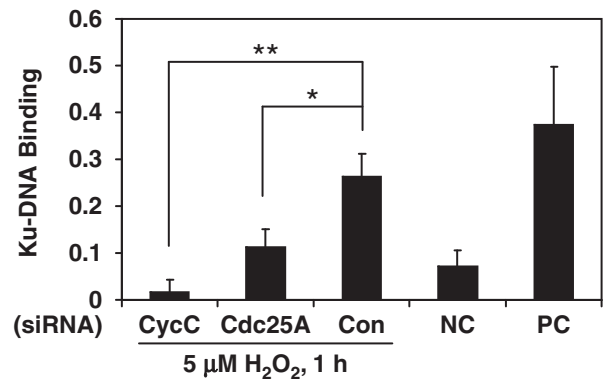

f
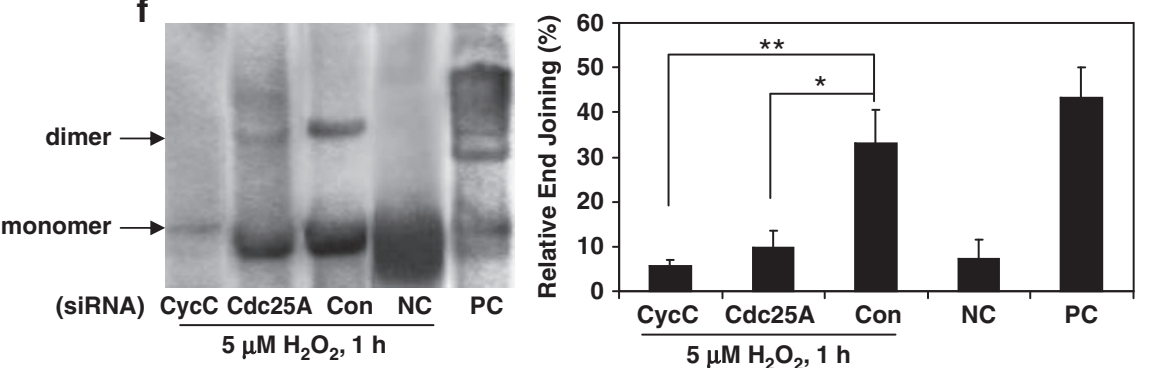

Figure 4 Blockade of cell-cycle entry attenuates NHEJ activation in postmitotic neurons. (a, b) Cortical neurons transfected either with cyclin-C (cycC), Cdc25A or control (Con) siRNA were exposed to $5 \mu \mathrm{M} \mathrm{H}_{2} \mathrm{O}_{2}$ for the indicated durations and analyzed by immunoblotting for the expression of cyclin-C and Cdc25A, or by immune precipitation (IP) with anti-cyclin-C antibody followed by in vitro kinase activity assay using Rb679 as substrate (IPK). Positive control (PC): lysates from proliferating HeLa cells. Isospecific control for anti-cyclin-C (IgG): normal rabbit IgG. (c, d) Immunoblot analysis of DSBs $(\gamma \mathrm{H} 2 \mathrm{AX})$ and apoptotic caspase-3 cleavage in neurons transfected either with cyclin-C (cycC), $\mathrm{Cdc} 25 \mathrm{~A}$ or control (Con) siRNA and exposed to $5 \mu \mathrm{M} \mathrm{H}_{2} \mathrm{O}_{2}$ for the indicated durations. Positive control (PC): Extracts from staurosporine-treated apoptotic Jurkat cells. (e) Ku-DNA binding of cortical neurons transfected with cyclin-C (cycC), Cdc25A or control (Con) siRNA and exposed to $5 \mu \mathrm{M} \mathrm{H}_{2} \mathrm{O}_{2}(1 \mathrm{~h}$ ). Negative control (NC): untreated untransfected cultures; positive control (PC): the nuclear extract of Raji cells. The values are the means and S.D. $(n=4) ;{ }^{*} P<0.01 ;{ }^{* *} P<0.001$. (f) NHEJ analysis of cortical neurons transfected with either cyclin-C (cycC), $\mathrm{Cdc} 25 \mathrm{~A}$ or control (Con) siRNA and exposed to $5 \mu \mathrm{M} \mathrm{H}_{2} \mathrm{O}_{2}$. Negative control (NC): untreated cultures; positive control (PC): T4 ligase-treated linearized plasmid DNA (pGL3 basic/Xhol). The values are the means and S.D. $(n=4) ;{ }^{*} P<0.005 ;{ }^{\star \star} P<0.001$

accompanied by DNA replication and apoptosis. ${ }^{23-26}$ In our experiments, p21 siRNA, unlike a control siRNA, reduced p21 protein levels and led to entry into S-phase, as demonstrated by the appearance of cyclin-E-associated pRb-kinase activity (Figures $5 a$ and b). Consistent with previous findings, ${ }^{24}$ postmitotic cortical neurons transfected with p21 siRNA underwent apoptosis by $24 \mathrm{~h}$ after transfection (Figure 5e). To avoid the S-phase entry and ensuing apoptosis, and to determine the direct impact of $\mathrm{G}_{0} \rightarrow \mathrm{G}_{1}$ transition on the DNA-repair machinery in postmitotic neurons, we combined p21 suppression with the targeting CDK2, critical for $G_{1} \rightarrow S$ transition. ${ }^{13}$ Since we observed cyclin-E-associated $\mathrm{pRb}$ activity by $4 \mathrm{~h}$ and apoptosis by $24 \mathrm{~h}$ after p21 siRNA transfection (Figures 5b, d and e), we decided to examine the expression of p21 and CDK2, as well as expression of cell-cycle markers (E2F1, cyclin-C-, cyclinD1 and cyclin-E-associated pRb-kinase activities), in cortical neurons cotransfected with p21 and CDK2 as early as $1 \mathrm{~h}$ after transfection. The specificity of the transfection was ascertained by the ability of siRNAs to lower p21 and CDK2 protein levels and to induce a massive early (by $1 \mathrm{~h}$ after transfection) re-entry of neurons into the cell cycle, but not Sphase, as measured by E2F1 expression, cyclin-C-, cyclinD1 but not cyclin-E-associated pRb-kinase activities, in contrast to the silencing of p21 alone (Figure 5). The specificity of transfection was also supported by the absence of apoptosis usually associated with S-phase entry (Figure 5e), and DSBs (the lack of $\gamma \mathrm{H} 2 \mathrm{AX}$ expression, which labels apoptotic cells) (Figure 5d). To determine whether $\mathrm{G}_{0} \rightarrow \mathrm{G}_{1}$ transition in postmitotic neurons is sufficient for initiation of NHEJ repair machinery, we determined the parameters of NHEJ activation in p21/CDK2 siRNA-transfected neurons. p21/CDK2 silencing initiated a significant increase in Ku-DNA-binding and DNA-PK activity (Figures $6 a$ and $b$ ). DNA-PK activity assay is based on kinase activity analysis of whole DNA complex composed of two subunits, Ku and DNA-PKcs. We next determined whether $\mathrm{G}_{0} \rightarrow \mathrm{G}_{1}$ transition induces end-joining activation. NHEJ activity in p21/CDK2 siRNA-transfected neurons was significantly higher than that in neurons transfected with control siRNA (Figure 6c). Importantly, NHEJ activation was short (1 and $2 \mathrm{~h}$ after transfection) and coincided with the timing of increased 
a

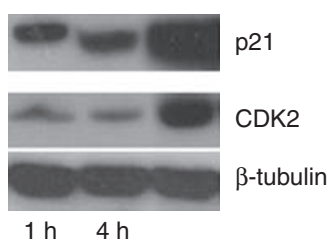

b

(siRNA) $\frac{1 \mathrm{~h} \quad 4 \mathrm{~h}}{\mathrm{p} 21+\mathrm{CDK} 2}$ Con

$1 \mathrm{~h}$ after

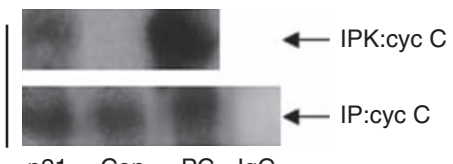

(siRnA) p21 Con PC IgG

+ CDK2

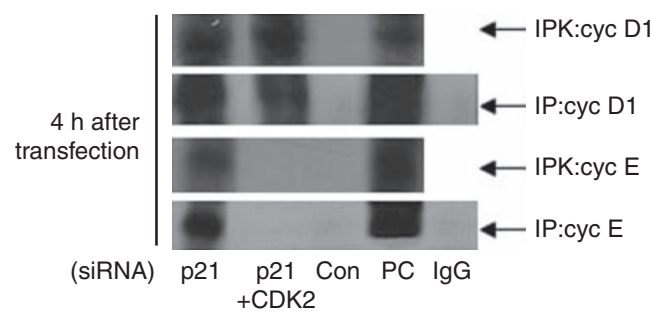

C

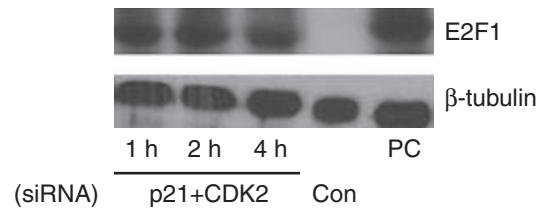

d

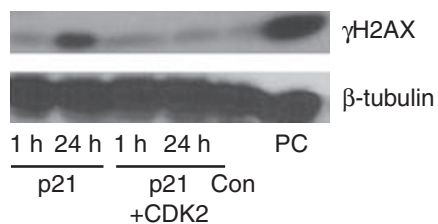

e $\quad 24 \mathrm{~h}$ after transfection Cleaved

caspase-3

(siRNA) p21 p21 Con PC

$\beta$-tubulin

+ CDK2

Figure 5 p21 silencing leads to S-phase entry, while co-targeting p21 and CDK2 reactivates only $G_{1}$. (a) Cortical neurons were transfected with either cyclin p21 or control (Con) siRNA, or co-transfected with p21 and CDK2 (p21/CDK2) siRNA. Expression of p21 and CDK3 was analyzed 1 and $4 \mathrm{~h}$ after transfection. (b) Cortical neurons were transfected either with p21, p21/CDK2 or control (Con) siRNA. In 1 and $4 \mathrm{~h}$ after transfection, the lysates were subjected to immune precipitation (IP) using anti-cyclin-C, anticyclin-D1 or anti-cyclin-E. Precipitates were tested for in vitro kinase activity using Rb679 as substrate (IPK). Positive control (PC): Lysates from proliferating HeLa cells. Isospefic controls for anti-cyclin-C, anti-cyclin-D1 and anti-cyclin-E (IgG): Normal rabbit and mouse IgG. (c) Immunoblot analysis of the expression of E2F1 in neurons transfection with p21/CDK2 or control (Con) siRNA. Positive control (PC): Proliferating HeLa cells. (d, e) Immunoblot analysis of $\gamma \mathrm{H} 2 \mathrm{AX}$ or cleaved caspase-3 expression in neurons transfected with p21, p21/CDK2 or control (Con) siRNA. Positive control (PC): Extract from staurosporine-treated apoptotic Jurkat cells. Note the appearance of $\gamma \mathrm{H} 2 \mathrm{AX}$ and the expression of cleaved caspase-3 only in cells transfected with p21, in contrast to neurons transfected with p21/CDK2 and control siRNA
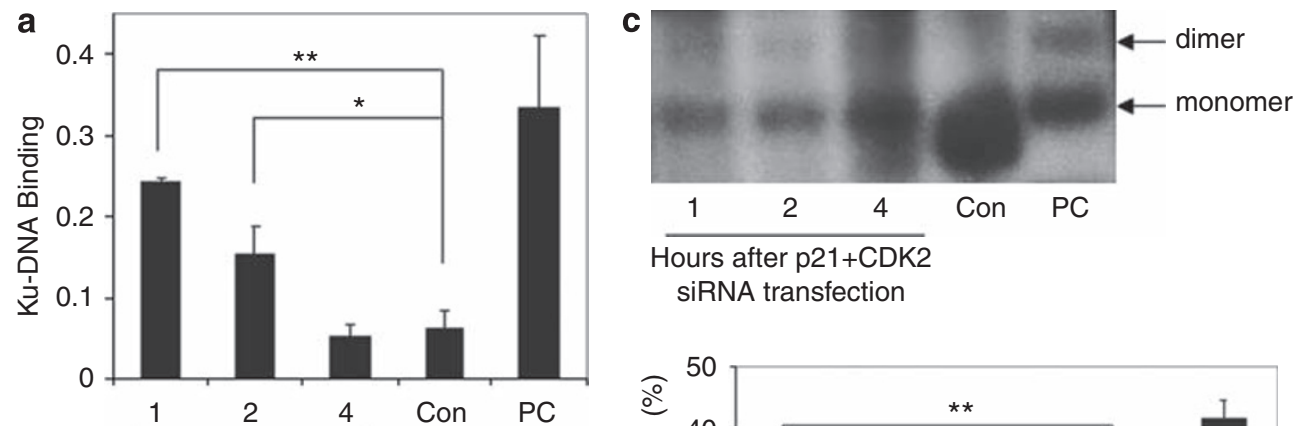

Hours after p21+CDK2

siRNA transfection

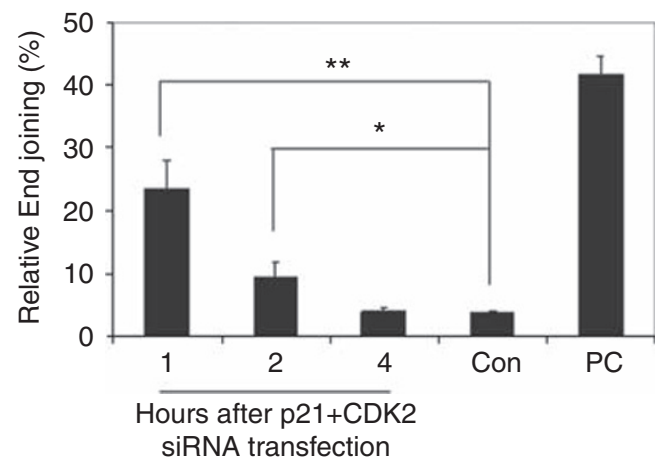

Figure 6 Forcing neurons into the cell cycle activates NHEJ in postmitotic neurons. (a) Ku-DNA binding analysis of cortical neurons transfected with p21/CDK2 or control (Con) siRNA. Positive control (PC): The nuclear extract of Raji cells. The values are the means and S.D. $(n=4) ;{ }^{*} P<0.01 ;{ }^{*} P<0.001$. (b) Cortical neurons were transfected with p21/CDK2 or control (Con) siRNA and after indicated time after transfection, DNA-PK activity was measured by kinase activity assay of whole DNA-PK complex. Positive control (PC): HeLa cells exposed to etoposide. (c) NHEJ analysis of cortical neurons transfected with either p21/CDK2 or control (Con) siRNA. Positive control (PC): T4 ligase-treated linearized plasmid DNA (pGL3 basic/Xhol). The values are the means and S.D. $(n=4) ;{ }^{\star} P<0.002 ;{ }^{* \star} P<0.001$ 
cyclin-C-associated pRb-kinase activity (Figure $5 b$ ), as it was observed in neurons exposed to $5 \mu \mathrm{M} \mathrm{H}_{2} \mathrm{O}_{2}$ (Figures 1 and 3).

\section{Discussion}

The expression of various canonical cell-cycle regulators in differentiated neurons of the adult brain observed under normal conditions, suggests that they have a physiological function, ${ }^{6,7}$ but this function remains unknown. Given the attenuation of the DNA-repair capacity following differentiation in most cell types, ${ }^{10,11}$ the expression of cell-cycle-related proteins may reflect the need for resting cells to re-enter the cell cycle to activate DNA repair. In mitotic cells, the cell-cycle machinery is an important component of the cellular response to DNA damage, involved in DNA repair and apoptosis. ${ }^{5} \mathrm{We}$ and others have demonstrated that cell-cycle activation is essential for DNA-damage-induced apoptosis., ${ }^{3,8,9}$ Here, we show that kinase activity involved in the cell's exit from $\mathrm{G}_{0}$, only recently established to be associated with cyclin-C, ${ }^{14}$ is required for activation of NHEJ repair in postmitotic neurons. Both increase in cyclin-C-associated pRb-kinase activity and NHEJ activation occurred shortly after cell's exposure to $\mathrm{H}_{2} \mathrm{O}_{2}$ and showed very similar kinetics. The fact that these cells are undergoing $G_{0} \rightarrow G_{1}$ transition is supported by our findings that E2F1 levels are elevated (this occurs as cells undergo $\mathrm{G}_{0} \rightarrow \mathrm{G}_{1}$ transition $^{13}$ ), and that $\mathrm{pRb}$ is phosphorylated at S807/811. Cyclin-D1 (but not cyclin-E)-associated pRbkinase activity was also induced as a result of DSB DNA damage, although cyclin-D1-associated pRb-kinase activity occurred outside of the time frame of NHEJ activity, suggesting that cyclin-D1-associated pRb-kinase activity may not be implicated in NHEJ repair. Thus, activation of NHEJ repair in postmitotic neurons was associated with entry into early $\mathrm{G} 1$, driven by cyclin-C-associated pRb-kinase activity, but it was not associated with late G1 progression directed by cyclin-E-dependent pRb-kinase activity.

The suppression of cyclin- $C$ by siRNA was shown to delay exit from $G_{0} .{ }^{14}$ We found that ablation of cyclin-C by siRNA significantly reduced cyclin-C-associated pRb-kinase activity induced by DNA damage, and attenuated NHEJ in neurons, as revealed by increased levels of $\gamma \mathrm{H} 2 \mathrm{AX}$. These changes, however, did not lead to apoptosis, suggesting that cell-cycle activation is important for both DNA repair and apoptosis in postmitotic cells. Indeed, numerous studies have demonstrated that suppression of cell-cycle signaling leads to attenuation of DNA-damage-initiated neuronal apoptosis. ${ }^{9,23,27}$ Thus, preventing cell-cycle activation disables both DNA repair and apoptosis, which may result in the accumulation of DNA lesions and cell death by a non-apoptotic mechanism. The effect of Cdc25A suppression on DSB DNA repair was not significantly different from the effect of cyclin-C ablation, although reduction of NHEJ activity was typically lower than in cells with reduced cyclin-C levels. We found that decreasing Cdc25A levels by siRNA attenuated cyclin-C-associated $\mathrm{pRb}$-kinase activity, providing evidence for the involvement of Cdc25A in this activity, in addition to previously established cyclin-E- and cyclin-D-associated pRb-kinase activities. ${ }^{23}$ Thus, impeding cyclin-C-associated $\mathrm{G}_{0}$ exit attenuates NHEJ DNA repair. This finding underscores the functional significance of $\mathrm{G}_{0} \rightarrow \mathrm{G}_{1}$ transition for NHEJ activation in postmitotic neurons.

Additional validation of the importance of early $\mathrm{G}_{1}$ for $\mathrm{NHEJ}$ repair in postmitotic neurons comes from our observation that forcing $G_{1}$ entry of postmitotic neurons induces NHEJ activation in the absence of DSB lesions. Previously, cells in quiescent states, including differentiation, were shown to be able to re-enter the cell cycle simply by removing appropriate CKIs. Interference with p21 was sufficient to reactivate the cell cycle and DNA synthesis in terminally differentiated skeletal muscle cells and quiescent fibroblasts. ${ }^{24}$ Reactivation of cell cycle and DNA replication has also been documented in quiescent cells overexpressing E2F1 and Cdc25A. ${ }^{23-26}$ Such reactivation of cell cycle and DNA replication were sufficient to promote neuronal death even in the absence of DNA damage. ${ }^{28}$ Given the possibility that DNA replication might play a decisive role in triggering apoptosis in differentiated cells forced into the cell cycle, we prevented DNA replication by silencing CDK2, an essential kinase for $\mathrm{G}_{1} \rightarrow \mathrm{S}$ transition. ${ }^{13}$ Indeed, joint silencing of p21 and CDK2 prevented both DNA replication and apoptosis, but did permit the initiation of cyclin-C-dependent pRb-kinase activity, exit from $\mathrm{G}_{0}$ and NHEJ induction.

Thus, our results demonstrate that cyclin-C-associated pRb-kinase activity and the associated progression through early $\mathrm{G} 1$ are crucial for NHEJ repair. This is evidenced by (1) the coincidence of the initiation of cyclin-C-associated pRb-kinase activity with NHEJ activation, (2) attenuation of NHEJ repair by impeding cyclin-C-associated pRb-kinase activity and (3) NHEJ activation in response to forced $G_{0} \rightarrow G_{1}$ transition. While cyclin-D1-associated pRb-kinase activity was induced in postmitotic neurons in response to DSBs or p21/CDK2 silencing, it occurred after cyclin-C-directed pRbkinase activity and after NHEJ was activated; thus, the role of cyclin-D1 in NHEJ activation remains to be established, as are the mechanisms preventing cells from initiation of cyclin$\mathrm{E}$-associated $\mathrm{pRb}$-kinase activity and $\mathrm{G}_{1} \rightarrow \mathrm{S}$ progression.

In contrast with repairable DNA damage, which only requires progression through early $\mathrm{G}_{1}$, DNA damage leading to neuronal death requires the cell-cycle machinery for entry into the S-phase and DNA replication in addition to $\mathrm{G}_{0} \rightarrow \mathrm{G}_{1}$ transition (cells cannot enter S-phase without $\mathrm{G}_{0} \rightarrow \mathrm{G}_{1}$ transition). ${ }^{9,24,28-32}$ Preventing DNA replication or S-phase entry attenuated apoptosis, while unrestricted progressing through $G_{1} \rightarrow S$ led to apoptosis. The fatal effect of DNA replication can be explained by the fact that DNA replication itself is a potential source of DNA damage, ${ }^{33}$ and unrepaired DNA lesions when they interfere with DNA replication, may lead to critical secondary lesions, which in turn may activate apoptotic signaling. ${ }^{34}$ Moreover, DNA replication in postmitotic neurons undergoing apoptosis involves a highly errorprone polymerase- $\beta$ (pol- $\beta$ ), normally engaged in DNA repair $^{35}$ instead of DNA polymerases, essential for canonical DNA synthesis. This may amplify DNA damage and generate apoptotic signaling in neurons if the DNA damage is not repaired.

Depending on multiple factors, including the source and extent of an insult, DNA damage results in either repair of damaged DNA or destruction of the cell by apoptosis. The mechanisms responsible for this decision are far from being elucidated. The two processes are not mutually exclusive and 


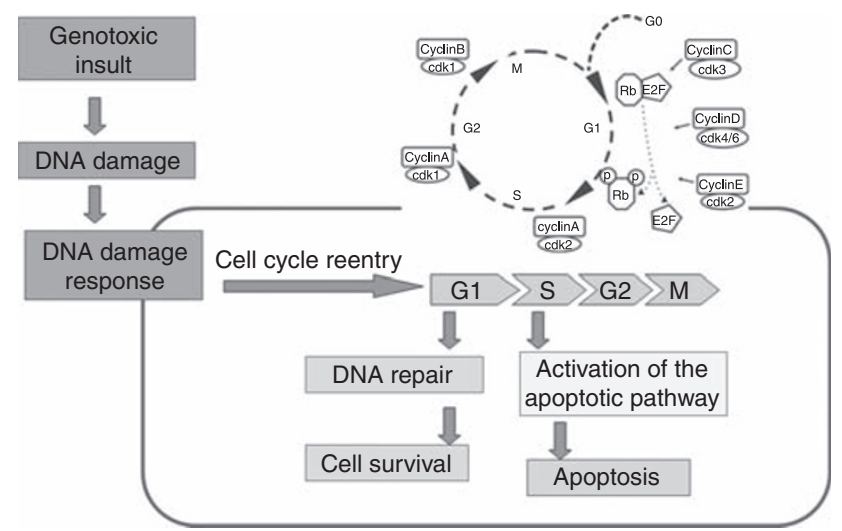

Figure 7 The hypothesized role of cell-cycle activation in response to DNA damage in postmitotic neurons. DNA damage generated by a genotoxic insult results in the activation of the DDR. Cell-cycle re-entry, which is an essential element of the DDR, plays a role in both DNA repair and apoptosis. $G_{1} \rightarrow S$ transition is critical for apoptotic signaling

are orchestrated by components implicated in both processes. According to our results, cell-cycle activation occurs in response to DNA damage and is involved in both DNA repair and apoptosis in postmitotic neurons. Figure 7 represents our model for the involvement of the cell-cycle machinery in the DDR of postmitotic neurons. The cell-cycle machinery may play a role in mechanisms that are part of the DDR orchestrated by the ataxia telangiectasia mutated (ATM) protein, the key regulator of the DSB signaling. ${ }^{36}$ It may also involve elements of the DNA-repair machinery such as Ku70/Ku86 proteins, which, besides their vital role in DNA repair, have been implicated in apoptosis ${ }^{37}$ and cell-cycle regulation. ${ }^{38}$

Our studies were focused on postmitotic neurons. Whether the role for early $G_{1}$ activation in DNA repair is limited to neurons and NHEJ, or may function in other types of terminally differentiated cells and other types of DNA-repair, remains to be addressed.

The integrity of DNA is constantly being challenged by genotoxic stress resulting from exogenous sources and most importantly, by oxyradicals produced by normal metabolic processes. ${ }^{1,2}$ Due to a high rate of oxygen metabolism, the DNA of postmitotic neurons is under increased risk of damage from free radicals. For humans, given that the life span of postmitotic neurons is many decades, competent DNA repair could be critical for neuronal survival. ${ }^{3}$ Since DNA-damaging events occur continuously in living cells, a protective DNArepair mechanism should be available. NHEJ activity and expression of cell-cycle markers were indeed observed in neurons of normal brain. ${ }^{6,7,39}$ Here, we demonstrate that this is not a coincidence. In response to DNA damage, neurons reenter the cell cycle and activate NHEJ. This is a permanent process in normal brain and this explains why both expression of cell-cycle markers and NHEJ activity were observed in brain under physiological conditions. The results of microdialysis applied to direct measurement of $\mathrm{H}_{2} \mathrm{O}_{2}$ in the rat striatum demonstrate that the $5 \mu \mathrm{M} \mathrm{H}_{2} \mathrm{O}_{2}$ used in our study is close to the concentrations of $\mathrm{H}_{2} \mathrm{O}_{2}$ in normal brain, ${ }^{40}$ underscoring the physiological implications of our results.

\section{Materials and Methods}

Antibody and reagents. The primary antibodies for immunoblotting and IP recognized cyclin-C (polyclonal, 1:1000; Abcam, Cambridge, MA, USA), Rb (polyclonal; 1: 1000; Pharmigen, San Jose, CA, USA), phospho-Rb at S807/S811 (polyclonal; 1 : 1000; Abcam), CDK3 (polyclonal; 1 : 1000; Abcam), p21 (polyclonal; 1: 1000; Abcam), CDK2 (polyclonal; 1: 1000; Abcam), үH2AX (polyclonal; 1;1000; Abcam), cleaved caspase-3 (polyclonal; 1:1000; Millipore, Temecula, CA, USA), cyclin-E (monoclonal; 1: 1000; Santa Cruz Biotechnology, Santa Cruz, CA, USA), cyclin-D1 (polyclonal; 1:1000; Santa Cruz Biotechnology), Cdc25A (polyclonal; 1: 1000; Santa Cruz Biotechnology), E2F1 (monoclonal; 1: 1000; Sigma, St Louis, MO, USA) or tubulin (polyclonal; 1:4000; Abcam). HRP-conjugated sheep antimouse lgG and donkey anti- rabbit lgG ( 1 : 5000; Amersham, Piscataway, NJ, USA) were used as secondary antibodies. The primary antibody for immunofluorescence recognized Ki-67 (polyclonal; 1:50; Abcam), phosphorylated at T2609 DNA-PKcs (polyclonal; 1:50; Genway, San Diego, CA, USA) or NeuN (monoclonal, 1:500; Millipore). Texas Red-conjugated goat anti-rabbit (1:200; Santa Cruz Biotechnology), Alexa-488-conjugated goat anti-mouse $(1: 200$; Invitrogen, Carlsbad, CA, USA) and Alexa350-conjugated goat anti-mouse (1:200; Invitrogen) antibodies were used as secondary antibodies. Rb769, a substrate for the in vitro kinase assay, normal rabbit and normal mouse lgG were purchased from Santa Cruz Biotechnology.

Cell culture. All experiments involving use of animals were approved by the IACUC at the TTUHSC. Primary cortical cell cultures were established from E18 Sprague-Dawley rats. The cells were plated according to procedures described earlier. ${ }^{9}$ Following dissociation by mild trypsinization and trituration, the cells were seeded onto plastic dishes or chamber slides precoated with $0.025 \mathrm{mg} / \mathrm{ml}$ poly-Llysine, at a density of $1.3 \times 103$ neurons $/ \mathrm{mm}^{2}$ in Neurobasal medium containing B-27 supplement, $1 \mathrm{mM}$ HEPES, $2 \mathrm{mM}$ glutamate and $0.001 \%$ gentamycin sulfate. All of the experiments were performed with 5-day-old cultures. A fresh stock of $1 \mathrm{mM}$ $\mathrm{H}_{2} \mathrm{O}_{2}$ (Sigma) was prepared in Neurobasal medium for each experiment and added at the indicated concentration.

Survival assays. Neuronal viability was assessed by quantifying apoptotic nuclei following the treatments. Cells were fixed and stained with the DNA-binding dye Hoechst $33258(1 \mu \mathrm{g} / \mathrm{ml}$; Sigma) and the percentage of cells with apoptotic nuclei was calculated as described previously. ${ }^{9}$ Nuclear staining was viewed and photographed using a Nikon Eclipse E800 fluorescence microscope equipped with a Spot digital camera and software. Apoptosis was also determined by immunoblot analysis for activated (cleaved) caspase-3 in cellular extracts from corresponding neuronal cultures. Extract from staurosporine-treated apoptotic Jurkat cells (Sigma) was used as a positive control.

Preparation of cell lysates. Cells were lysed after washing with cold PBS by incubation in ice-cold RIPA buffer containing a protease inhibitor cocktail (Calbiochem, San Diego, CA, USA), $1 \mathrm{mM} \mathrm{NaF}$ and $0.5 \mathrm{mM} \mathrm{Na}_{3} \mathrm{VO}_{4}$ before collection by scraping and sonication, and centrifugated at 14000 r.p.m. for $15 \mathrm{~min}$ at $4{ }^{\circ} \mathrm{C}$. The resulting supernatant was collected as the total-cell extracts used for immunoblotting, IP, NHEJ assay and Ku-binding assays. For preparation of nuclear extract used for immunoblotting of $\gamma \mathrm{H} 2 \mathrm{AX}$, cortical neurons were lysed in ice-cold buffer containing protease inhibitor cocktail (Calbiochem) and incubated with hydrochloric acid $(0.2 \mathrm{M})$ on ice for $30 \mathrm{~min}$. After centrifugation, the acid-insoluble pellet was discarded and the supernatant was dialyzed twice against $200 \mathrm{ml} 0.1 \mathrm{M}$ acetic acid (1-2 $\mathrm{h}$ each time) and then dialyzed against water.

Immunoblotting and immunoprecipitation. The protein concentrations of the lysates were measured with the Bio-Rad protein assay reagent. Total-cell or nuclear lysates (20-100 $\mu \mathrm{g}$ protein), or immune precipitates, were separated by SDS-PAGE and electrophoretically transferred to PVDF membranes (Millipore) and probed with the appropriate antibodies. Blots were then incubated with HRP-conjugated secondary antibodies and developed using Enhanced Chemiluminescence Reagent Pico (Pierce, Rockford, IL, USA). For immunoprecipitation, lysates $(200-800 \mu \mathrm{g})$ were incubated with the appropriate antibody overnight at $4{ }^{\circ} \mathrm{C}$ followed by incubation for $1 \mathrm{~h}$ with protein-A/GSepharose beads (Santa Cruz Biotechnology). The immune complexes were washed two times with RIPA buffer, boiled and separated by SDS-PAGE or used for the in vitro kinase assay. The immunoblot band intensities were normalized to $\beta$ tubulin or $\mathrm{pRb}$ (for ppRb S807/S811). Quantification was performed using the Image software (Quantity one-4.6; Bio-Rad, Hercules, CA, USA). 
Preparation of substrate DNA and analysis of NHEJ activity. Using the Xhol enzyme we designed the substrate DNA for the endjoining assay that generated a linear dimer as a reaction product, without the formation of circular monomers by linearizing pGL3 basic (a gift from Dr P Makhov; Fox Chase Cancer Center). DNA fragments was purified on Qiagen spin columns, precipitated with $95 \%$ ethanol and resuspended to $1 \mu \mathrm{g} / \mu \mathrm{l}$ in Tris buffer (TE). Endjoining assays using total-cell extracts dialyzed against $50 \mathrm{mM}$ Tris $(\mathrm{pH} 8.0), 20 \mathrm{mM}$ potassium acetate, $20 \%$ glycerol, $1 \mathrm{mM}$ EDTA and $5 \mathrm{mM}$ cysteine were performed as previously described. ${ }^{21,22}$ The dialyzed extracts were normalized for their respective total protein levels using the Bio-Rad protein assay. The reactions (40-60 $\mu \mathrm{g}$ protein) were performed in $50 \mathrm{mM}$ TRIS $(\mathrm{pH} 7.5), 0.5 \mathrm{mM} \mathrm{Mg}(\mathrm{OAc})_{2}$, $60 \mathrm{mM}$ potassium acetate, $2 \mathrm{mM} \mathrm{ATP}, 1 \mathrm{mM} \mathrm{DTT}, 0.1 \mathrm{mg} / \mathrm{ml} \mathrm{BSA}$ and $0.5 \mu \mathrm{g}$ of the linearized plasmid DNA. The samples were incubated at $37^{\circ} \mathrm{C}$ for $2 \mathrm{~h}$ and then deproteinized using a phenol : chloroform : isoamyl alcohol solution (USB), and DNA was precipitated by ethanol and dissolved in TE buffer. The purified DNA substrate was separated by electrophoresis on $0.8 \%$ agarose gels. For Southern blot analysis, the gel was depurinated and blotted onto a nylon membrane (Hybond $\mathrm{N}+$; Amersham) in denaturating buffer (alkaline transfer). The membrane was hybridized with the ${ }^{32} \mathrm{P}$-labeled plasmid ( $\mathrm{pGL} 3$ basic) probe prepared using the Random primer labeling kit (Stratagene, La Jolla, CA, USA). As positive control, we used T4 ligase (New England Biolabs, Ipswich, MA, USA)-treated linearized plasmid DNA (pGL3 basic/Xhol). The end-joined products were visualized by autoradiography. Quantification of the intensity of the Southern blot band was performed using the Image software (Quantity one-4.6; Bio-Rad). The percentage of rejoining was calculated by the sum of dimer and multimer divided by the sum of monomer, dimer and multimer.

DNA-PK assay. The kinase activity of DNA-PK was determined using the Signa TECTTM DNA-dependent Protein Kinase Assay System (Promega, Madison, WI, USA). In brief, $10 \mu \mathrm{g}$ of nuclear extract was incubated with an activator DNA, a biotinylated p53-derived peptide substrate and $\left[\gamma^{32} \mathrm{P}\right] \mathrm{ATP}$ at $30^{\circ} \mathrm{C}$ for $5 \mathrm{~min}$. The reaction was terminated by adding termination buffer. Each termination reaction sample was spotted onto a SAM2TM Biotin Capture Membrane and washed with $2 \mathrm{M} \mathrm{NaCl}$ and $2 \mathrm{M} \mathrm{NaCl}$ in $1 \% \mathrm{H}_{3} \mathrm{PO}_{4}$. The SAM2TM Membrane squares were analyzed using a Molecular Imager System (Bio-Rad).

siRNA transfection. siRNA oligonucleotides targeting cyclin-C, Cdc25A, p21 and CDK2 (SMARTpool reagents; Dharmacon, Lafayette, CO, USA), each representing a cocktail of four siRNAs directed against different regions of corresponding genes, were designed and used according to the manufacturer's guidelines. siRNA oligonucleotides targeting MAPK1 (Qiagen, Valencia, CA, USA) was used as a control siRNA. Double-stranded siRNAs were generated by adding the corresponding mixture of siRNA nucleotides to siRNA buffer (Dharmacon, Lafayette, CO, USA) to obtain a 50-mM solution. The reaction mixture was heated to $90^{\circ} \mathrm{C}$ for $1 \mathrm{~min}$ and stored at $-20^{\circ} \mathrm{C}$. Transfection of RNA oligonucleotides was performed using the RNAi Starter kit (Qiagen) according to the manufacturer's recommendations, with a final oligonucleotide concentration of 50 or $100 \mathrm{nM}$ (for cotransfection of p21 and CDK2 RNAi, $50 \mathrm{nM}$ of each RNAi was used). After $24 \mathrm{~h}$ (for cyclin-C and Cdc25A siRNA), viability and protein expression were assessed in lysates collected in $1 \mathrm{~h}$ after treatment of transfected cells with $5 \mu \mathrm{M} \mathrm{H}_{2} \mathrm{O}_{2}$, by western blotting using primary antibodies recognizing either cyclin-C or Cdc25A The viability and protein expression in neurons transfected with p21 and p21/CDK2 siRNA were assessed after 1 and $4 \mathrm{~h}$ after transfection.

Measurement of Ku70/Ku86 (Ku)-DNA-binding activity. Ku70/Ku86 DNA-binding activity was analyzed by using a Ku70/Ku86 DNA Repair kit (Active Motif, Carlsbad, CA, USA). Briefly, cells were washed and resuspended in hypotonic buffer. The nuclear extract was isolated for Ku activity analysis. A 5- $\mu \mathrm{g}$ weight of cell extract protein was loaded into the oligonucleotide-coated, 96-well plate and incubated for $60 \mathrm{~min}$ at room temperature. Ku70 or Ku86 antibody was added and incubated for another $60 \mathrm{~min}$. After washing, HRP-conjugated secondary antibody was added and incubated for $60 \mathrm{~min}$. After washing, the developing solution and stop solution were added. Optical density was read at $450 \mathrm{~nm}$ using a spectrophotometer. Each experiment was repeated three times and data represent the mean \pm S.D. of three separate determinations.

In vitro kinase assays. Cyclin-C-, cyclin-D1- and cyclin-E-associated kinase activities were assayed as described. ${ }^{14}$ Briefly, $200 \mu \mathrm{g}$ of protein from total-cell lysate was incubated with either $2.5 \mu \mathrm{g}$ anti-cyclin-C, anti-cyclin-D1 or anti-cyclin-E overnight at $4{ }^{\circ} \mathrm{C}$. Then $20 \mu \mathrm{l}$ of $50 \%$ slurry protein- $\mathrm{A} / \mathrm{G}$ agarose beads were added and incubated for $1-2 \mathrm{~h}$ at $4{ }^{\circ} \mathrm{C}$. The beads were washed twice with RIPA buffer, twice with kinase buffer $\left(50 \mathrm{mM}\right.$ Tris- $\mathrm{HCl}(\mathrm{pH} 7.5) 150 \mathrm{mM} \mathrm{NaCl}, 10 \mathrm{mM} \mathrm{MgCl}_{2}$, $1 \mathrm{mM}$ DTT) and resuspended in $20 \mu \mathrm{l}$ of kinase buffer containing $20 \mu \mathrm{M} \mathrm{ATP}, 1 \mu \mathrm{l}$ $\left[\gamma^{32}\right.$ P]ATP (3000 Ci/mmol; PerkinElmer Life Sciences, Waltham, MA, USA), $0.45 \mu \mathrm{g} \mathrm{Rb}-769$ (Santa Cruz Biotechnology). The reaction was incubated for $30 \mathrm{~min}$ at $30^{\circ} \mathrm{C}$. The reaction was stopped by adding $3 \mu$ of $6 \times$ SDS-PAGE sample buffer with subsequent boiling. The samples were resolved by SDS-PAGE and electrophoretically transferred to PVDF membranes. The products of the kinase reaction were visualized by autoradiography.

Immunofluorescence. Neurons grown on glass coverslips were fixed in freshly prepared $4 \%$ formaldehyde for $30 \mathrm{~min}$ at $4{ }^{\circ} \mathrm{C}$ and then permeabilized for $10 \mathrm{~min}$ in $0.1 \%$ Triton X-100 in 1\% BSA prepared in PBS, blocked in $1 \%$ BSA for $1 \mathrm{~h}$ at room temperature and double-stained with NeuN and Ki-67 or NeuN and T2609 DNA-PKcs primary antibodies for $45 \mathrm{~min}$ at $37^{\circ} \mathrm{C}$ followed by PBS $/ 0.1 \%$ Triton washing and staining with appropriate secondary antibodies. The coverslips were mounted with the Vectashield mounting medium (Vector Laboratories, Burlingame, CA, USA) and examined with a Nikon Eclipse E800 fluorescence microscope equipped with a Spot digital camera and software.

Statistical analyses. Statistical analyses were performed with Microsoft Excel and $P$-values were obtained by ANOVA and Fisher's post hoc test. A $P$-value $<0.05$ was considered significant.

\section{Conflict of interest}

The authors declare no conflict of interest.

Acknowledgements. We thank Raul Perez-Olle for helpful discussions and P Makhov for the pGL3 basic vector. This work was supported by the Garrison Institute on Aging, TTUHSC. MG was funded by the NIA-IRP, NIH.

1. Bassing $\mathrm{CH}$, Alt FW. The cellular response to general and programmed DNA double strand breaks. DNA Repair (Amst) 2004; 3: 781-796.

2. Lavin MF, Kozlov S. DNA damage-induced signalling in ataxia-telangiectasia and related syndromes. Radiother Oncol 2007; 83: 231-237.

3. Fishel ML, Vasko MR, Kelley MR. DNA repair in neurons: so if they don't divide what's to repair? Mutat Res 2007; 614: 24-36

4. Biton S, Barzilai A, Shiloh Y. The neurological phenotype of ataxia-telangiectasia: solving a persistent puzzle. DNA Repair (Amst) 2008; 7: 1028-1038

5. Rhind N, Russell P. Checkpoints: it takes more than time to heal some wounds. Curr Biol 2000; 10: R908-R911.

6. Schmetsdorf S, Gärtner U, Arendt T. Constitutive expression of functionally active cyclindependent kinases and their binding partners suggests noncanonical functions of cell cycle regulators in differentiated neurons. Cereb Cortex 2007; 17: 1821-1829.

7. Schmetsdorf S, Arnold E, Holzer M, Arendt T, Gärtner U. A putative role for cell cycle-related proteins in microtubule-based neuroplasticity. Eur J Neurosci 2009; 29: 1096-10107.

8. Becker EB, Bonni A. Cell cycle regulation of neuronal apoptosis in development and disease. Prog Neurobiol 2004; 72: 1-25.

9. Kruman II, Wersto RP, Cardozo-Pelaez F, Smilenov L, Chan SL, Chrest FJ et al. Cell cycle activation linked to neuronal cell death initiated by DNA damage. Neuron 2004; 41: 549-561.

10. McMurray CT. To die or not to die: DNA repair in neurons. Mutat Res 2005; $577: 260-274$

11. Narciso L, Fortini $P$, Pajalunga D, Franchitto $A$, Liu $P$, Degan $P$ et al. Terminally differentiated muscle cells are defective in base excision DNA repair and hypersensitive to oxygen injury. Proc Natl Acad Sci USA 2007; 104: 17010-17015.

12. Schwartz El, Smilenov LB, Price MA, Osredkar T, Baker RA, Ghosh S et al. Cell cycle activation in postmitotic neurons is essential for DNA repair. Cell Cycle 2007; 6: 318-329.

13. Nevins JR. The Rb/E2F pathway and cancer. Hum Mol Genet 2001; 10: 699-703.

14. Ren $S$, Rollins BJ. Cyclin $C / C d k 3$ promotes Rb-dependent $G_{0}$ exit. Cell 2004; 117 : 239-251.

15. Zhang J, Ghio AJ, Gao M, Wei K, Rosen GD, Upadhyay D. Ambient particulate matter induces alveolar epithelial cell cycle arrest: role of $G_{1}$ cyclins. FEBS Lett 2007; 581: 5315-5320.

16. Khanna KK, Jackson SP. DNA double-strand breaks: signaling, repair and the cancer connection. Nat Genet 2001; 27: 247-254.

17. Yano K, Morotomi-Yano K, Adachi N, Akiyama H. Molecular mechanism of protein assembly on DNA double-strand breaks in the non-homologous end-joining pathway. $J$ Radiat Res (Tokyo) 2009; 50: 97-108.

18. Lea NC, Orr SJ, Stoeber K, Williams GH, Lam EW, Ibrahim MA et al. Commitment point during $G_{0} \rightarrow G_{1}$ that controls entry into the cell cycle. Mol Cell Biol 2003; 23: 2351-2361. 
19. Grawunder U, Finnie N, Jackson SP, Riwar B, Jessberger R. Expression of DNA-dependent protein kinase holoenzyme upon induction of lymphocyte differentiation and V(D)J recombination. Eur J Biochem 1996; 241: 931-940.

20. Diggle CP, Bentley J, Kiltie AE. Development of a rapid, small-scale DNA repair assay for use on clinical samples. Nucleic Acids Res 2003; 31: e83.

21. Chan DW, Chen BP, Prithiviraisingh S, Kurimasa A, Story MD, Qin $J$ et al. Autophosphorylation of the DNA-dependent protein kinase catalytic subunit is required for rejoining of DNA double-strand breaks. Genes Dev 2002; 16: 2333-2338.

22. Ding Q, Reddy YV, Wang W, Woods T, Douglas P, Ramsden DA et al. Autophosphorylation of the catalytic subunit of the DNA-dependent protein kinase is required for efficient end processing during DNA double-strand break repair. Mol Cell Biol 2003; 23: 5836-5848

23. Zhang Y, Qu D, Morris EJ, O'Hare MJ, Callaghan SM, Slack RS et al. The Chk1/Cdc25A pathway as activators of the cell cycle in neuronal death induced by camptothecin. J Neurosci 2006; 26: 8819-8828.

24. Pajalunga D, Mazzola A, Salzano AM, Biferi MG, De Luca G, Crescenzi M. Critical requirement for cell cycle inhibitors in sustaining nonproliferative states. J Cell Biol 2007; 176: 807-818.

25. Smith DS, Leone G, DeGregori J, Ahmed MN, Qumsiyeh MB, Nevins JR. Induction of DNA replication in adult rat neurons by deregulation of the retinoblastoma/E2F $\mathrm{G}_{1}$ cell cycle pathway. Cell Growth Differ 2000; 11: 625-633.

26. Rogoff HA, Kowalik TF. Life, death and E2F: linking proliferation control and DNA damage signaling via E2F1. Cell Cycle 2004; 3: 845-846.

27. Alvira D, Yeste-Velasco M, Folch J, Casadesús G, Smith MA, Pallàs M et al. Neuroprotective effects of caffeine against complex I inhibition-induced apoptosis are mediated by inhibition of the Atm/p53/E2F-1 path in cerebellar granule neurons. $J$ Neurosci Res 2007; 85: 3079-3088

28. O'Hare MJ, Hou ST, Morris EJ, Cregan SP, Xu Q, Slack RS et al. Induction and modulation of cerebellar granule neuron death by E2F-1. J Biol Chem 2000; 275: 25358-25364.
29. Neve RL, McPhie DL. Dysfunction of amyloid precursor protein signaling in neurons leads to DNA synthesis and apoptosis. Biochim Biophys Acta 2007; 1772: 430-437.

30. Klein JA, Longo-Guess CM, Rossmann MP, Seburn KL, Hurd RE, Frankel WN et al. The harlequin mouse mutation downregulates apoptosis-inducing factor. Nature 2002; 419 367-374.

31. Kuan CY, Schloemer AJ, Lu A, Burns KA, Weng WL, Williams MT et al. Hypoxia-ischemia induces DNA synthesis without cell proliferation in dying neurons in adult rodent brain. J Neurosci 2004; 24: 10763-10772.

32. Höglinger GU, Breunig JJ, Depboylu C, Rouaux C, Michel PP, Alvarez-Fischer D et al. The $\mathrm{pRb} / \mathrm{E} 2 \mathrm{~F}$ cell-cycle pathway mediates cell death in Parkinson's disease. Proc Natl Acad Sci USA 2007; 104: 3585-3590.

33. Ruzankina Y, Asare A, Brown EJ. Replicative stress, stem cells and aging. Mech Ageing Dev 2008; 129: 460-466.

34. Roos WP, Kaina B. DNA damage-induced cell death by apoptosis. Trends Mol Med 2006; 12: $440-450$.

35. Copani A, Sortino MA, Caricasole A, Chiechio S, Chisari M, Battaglia G et al. Erratic expression of DNA polymerases by beta-amyloid causes neuronal death. FASEB J 2002; 16: 2006-2008.

36. Shiloh Y. The ATM-mediated DNA-damage response: taking shape. Trends Biochem Sci 2006; 31: 402-410.

37. Downs JA, Jackson SP. A means to a DNA end: the many roles of Ku. Nat Rev Mol Cell Bio 2004; 5: 367-378

38. Rampakakis E, Di Paola D, Zannis-Hadjopoulos M. Ku is involved in cell growth, DNA replication and $\mathrm{G}_{1} \rightarrow \mathrm{S}$ transition. J Cell Sci 2008; 121: 590-600.

39. Sharma S. Age-related nonhomologous end joining activity in rat neurons. Brain Res Bull 2007; 73: 48-54.

40. Hyslop PA, Zhang Z, Pearson DV, Phebus LA. Measurement of striatal $\mathrm{H}_{2} \mathrm{O}_{2}$ by microdialysis following global forebrain ischemia and reperfusion in the rat: correlation with the cytotoxic potential of $\mathrm{H}_{2} \mathrm{O}_{2}$ in vitro. Brain Res 1995; 671: 181-186. 